\title{
VALIDATION OF THE METROLOGICAL MODEL OF COORDINATE MEASURING ARM USING MULTIFEATURE CHECK
}

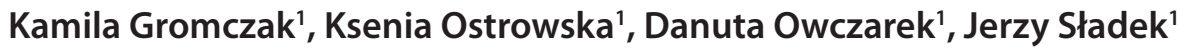 \\ 1 Laboratory of Coordinate Metrology, Faculty of Mechanical Engineering, Cracow University of Technology, \\ Jana Pawła II 37, 31-864 Kraków, Poland, e-mail: kgromczak@mech.pk.edu.pl, kostrowska@mech.pk.edu.pl, \\ dszewczyk@mech.pk.edu.pl,sladek@mech.pk.edu.pl
}

Received: 2015.09 .19

Accepted: 2015.11.14

Published: 2015.12.04

\begin{abstract}
The article presents the validation research scheme of metrological model of coordinate measuring arm (CMA) using multifeature check. The scheme shows the comparison of the calibration results of the check using selected coordinate methods and criteria of validation. The comparison shows the insignificance of differences between the obtained results of both: metrological model of CMA and multi-position method. It evidently proves the correctness of the development of metrological model of CMA. The use of appropriate quality multifeature check also had a significant impact on the results. This check is now the most accurate measurement length check and its use for this validation process was the most suitable.
\end{abstract}

Keywords: validation, metrological model, coordinate measuring arm.

\section{INTRODUCTION}

Coordinate metrology is a rapidly developing field of science. Nowadays, we can see running coordinate measuring systems in almost every manufacturing institute. Increasing quality requirements for products provide new challenges for manufacturers of measurement systems. One of the fastest growing redundant systems are solutions which include of coordinate measuring arms (CMA). These devices conquered the market because they are mobile, hand-held and have a good ratio of price to the accuracy. We can also use them to measure large-scale components using systems which increase the range such as gridlock or SpaceLock.

According to the assumptions of metrology, measurement results are only useful when you are presented with uncertainty. But it is a very complex process because of the insignificant availability of the uncertainty of measurement methods which are usually dedicated to research centers, such as multi-position method and substitution method. This is due to the complexity of the process and the need to use various measuring checks.
In recent years, new methods called simulation methods have been developed. These methods require an earlier development of the socalled virtual measuring devices used to assess the accuracy of on-line measurements. Virtual measuring devices are based on the so-called metrology model which should accurately reflect the behavior of the actual measuring machine.

In this paper, the verification of metrological model of actual CMA was presented, done by checking the accuracy of the determined parameters measured on a multi-feature check. Selected values of the check measured first in the software of the device and then using programmed metrological model of CMA were compared with the reference values using an appropriate validation model.

\section{DESCRIPTION OF THE METROLOGICAL MODEL OF CMA}

Metrological model of redundant measuring devices is based on the determination of:

- accurate geometrical dimensions of the individual units, 
- simple kinematics tasks.

Metrological model is based on a kinematic description of the device, where as a basis for dimensional analysis a description, in accordance with the Denavit-Harterberg (D-H) notation, was assumed. This notation is associated with each joint of local coordinate system (Fig. 1). Using a simple kinematics task, a string transformation of neighboring coordinate systems need to be specified so as to determine the position and orientation of the latter unit relative to the first unit of the device.

On the basis of the kinematic scheme the matrices of further transformations of coordinate systems need to be determined:

$A_{i}^{i-1}=\left[\begin{array}{cccc}\cos \theta_{i} & -\cos \alpha_{i} \sin \theta_{i} & \sin \alpha_{i} \sin \theta_{i} & l_{i} \cos \theta_{i} \\ \sin \theta_{i} & \cos \alpha_{i} \cos \theta_{i} & -\sin \alpha_{i} \cos \theta_{i} & l_{i} \sin \theta_{i} \\ 0 & \sin \alpha_{i} & \cos \alpha_{i} & \lambda_{i} \\ 0 & 0 & 0 & 1\end{array}\right]$

where:

where:

$$
A_{i}^{i-1}=\left[\begin{array}{cccc}
B & & & p \\
0 & 0 & 0 & 1
\end{array}\right]
$$

$$
\begin{gathered}
B_{i}=\left[\begin{array}{lll}
n_{i} & o_{i} & a_{i}
\end{array}\right]=\left[\begin{array}{lll}
n_{\dot{x}} & o_{\dot{x}} & a_{\dot{k}} \\
n_{\dot{y}} & o_{\dot{y}} & a_{\dot{y}} \\
n_{\dot{z}} & o_{\dot{z}} & a_{\dot{z}}
\end{array}\right] \\
p_{i}=\left[\begin{array}{lll}
p_{\dot{x}} & p_{\dot{y}} & p_{\dot{z}}
\end{array}\right]^{T},
\end{gathered}
$$

where: $B_{i}$ - orientation matrix,

$p_{i}-$ position matrix,

$p_{i x}, p_{i y}, p_{i z}-$ coordinates of the position of suitable unit,

$n_{i x}, n_{i y}, n_{i z}, o_{i x}, o_{i y}, o_{i z}, a_{i x}, a_{i j}, a_{i z}$ - coordinates of vector describing the rotation of the individual elements

The next step is to determine the so-called simple kinematics task. This is a static-geometric task, which can be regarded as the task of mapping of description of the location of the device from the configuration coordinates space to the description of Cartesian coordinates space. The matrix of the position and orientation of system $\mathrm{n}$ relative to the system associated with the unit $i$ can be written as the product of successive transformations:

$$
A_{i}^{i-1}=A_{1}^{0} A_{2}^{1} A_{3}^{2} \ldots A_{i}^{i-1}
$$

where: $A$ - matrix describing the location and orientation of the individual units, $\mathrm{T}$ - transformation matrix of matrix $A$.

Next steps relate to the determination of the simple kinematic task in a symbolic way. This task has stored information about the position and orientation of the measuring stylus. Then (by comparing the relevant parameters with data from the manufacturer software) a system of equations

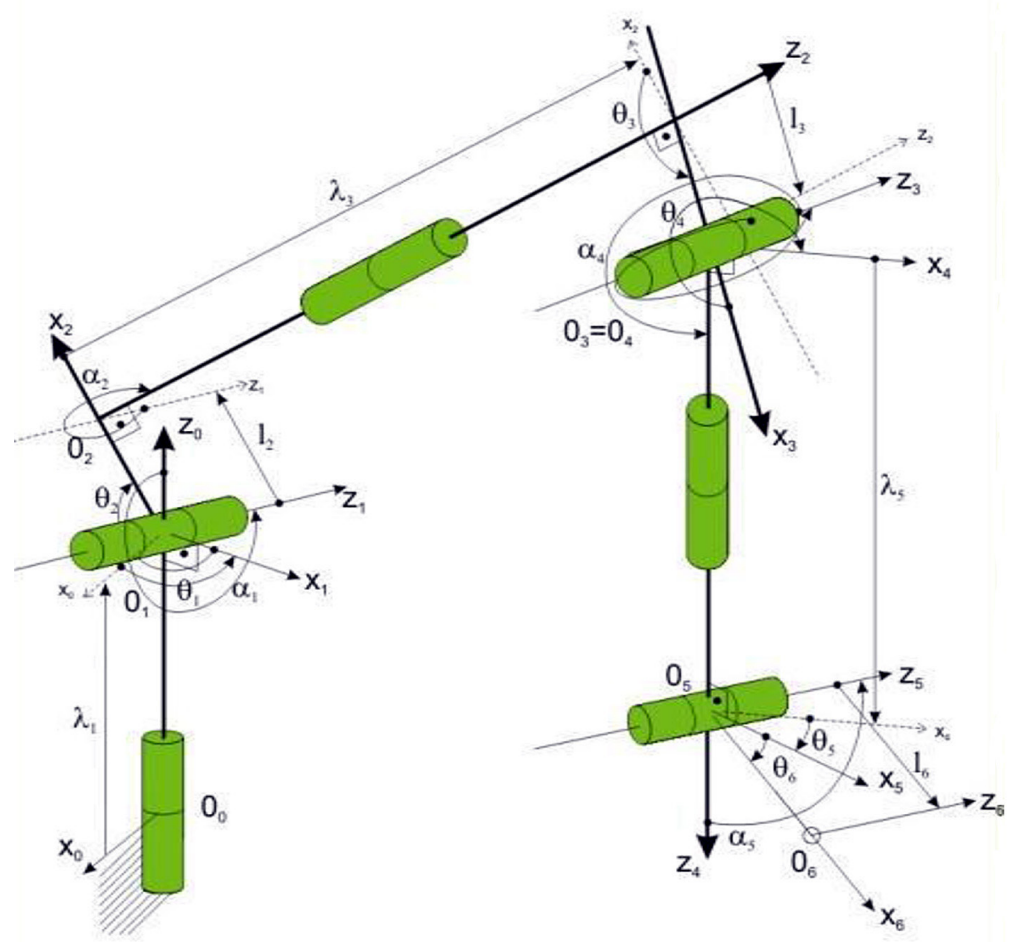

Fig. 1. Description of the device with an open kinematic chain with Denavit-Harterberg notation 
need to be built (6), which contains 28 unknowns describing the parameters needed to characterize the individual elements of the kinematic scheme, recorded in accordance with D-H notation, such as length of the units, as well as eccentrics, the angles between the axes, zero offset i.e. a difference between a true indication of the encoder and the projection assumptions (Fig. 1). The algorithm of determination of the parameters is shown in Figure 2.

In order to obtain relevant data sets, length check in several settings in the measurement space should be measured. From the manufacturer's software, we read the configuration coordinates $\theta_{i}$ (readings from the encoders), A, B, C (unit vectors describing the direction of the measuring stylus) and also cartesian coordinates $\mathrm{x}, \mathrm{y}$, $z$. Then we read the nominal data from the length check $x_{n}, y_{n}, z_{n}$. After obtaining data from an actual measuring device, as well as the check, we insert data into the equation (6):

$$
D_{1}=\sqrt{\left(X_{1 S}-X_{2 S}\right)^{2}+\left(Y_{1 S}-Y_{2 S}\right)^{2}+\left(Z_{1 S}-Z_{2 S}\right)^{2}}
$$

where: $D_{1}-$ distance of two points on the length check,
$X_{1 \mathrm{~S}}$ - model on the coordinate $\mathrm{X}$ of point 1 on the check determined from a simple task, $X_{2 \mathrm{~S}}-$ model on the coordinate $\mathrm{X}$ of point 2 on the check determined from a simple task, $Y_{1 \mathrm{~S}}-$ model on the coordinate $\mathrm{Y}$ of point 1 on the check determined from a simple task, $Y_{2 \mathrm{~S}}$ - model on the coordinate $\mathrm{Y}$ of point 2 on the check determined from a simple task, $Z_{1 \mathrm{~S}}-$ model on the coordinate $\mathrm{Z}$ of point 1 on the check determined from a simple task, $Z_{2 \mathrm{~S}}$ - model on the coordinate $\mathrm{Z}$ of point 2 on the check determined from a simple task.

We obtain an accurate geometrical description of each parameters. As, for the calculation, we have 28 variables, we have to build 28 equations and each of the equations will be built in an analogous way [1-7].

\section{VALIDATION OF THE METROLOGICAL MODEL OF CMA}

\section{Measurements using multifeature check}

The measurements by coordinate measuring arm RA7320SI (Fig. 3a) were carried out in

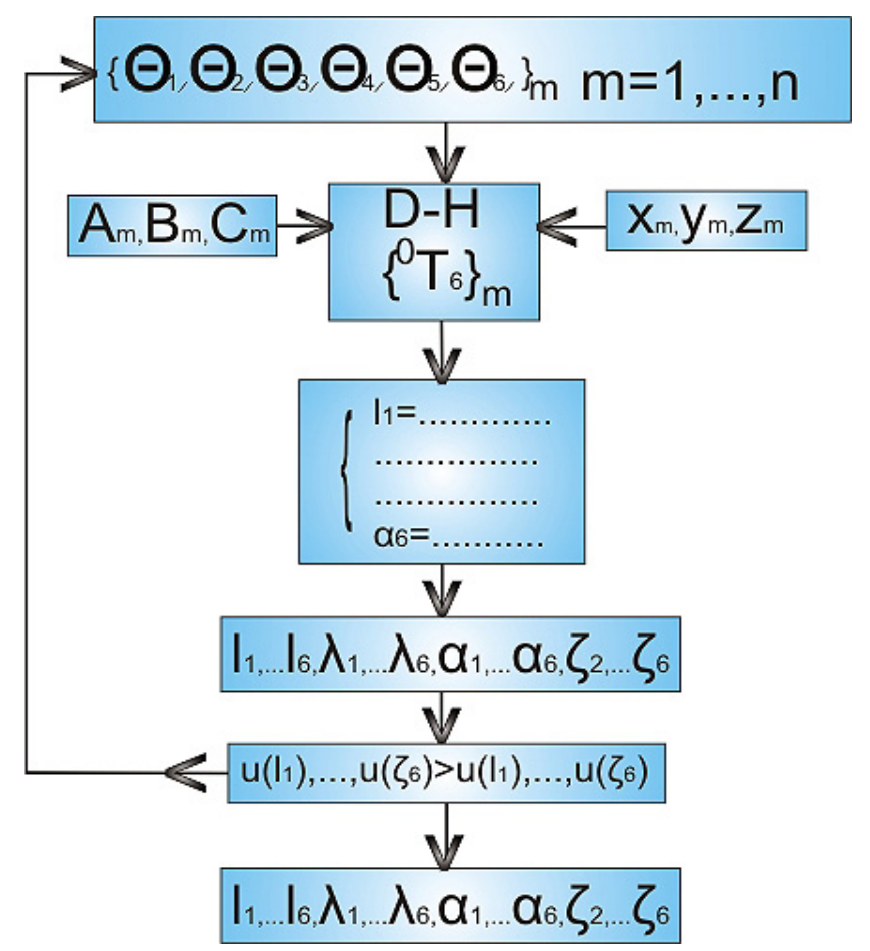

Fig. 2. The algorithm for calculating the geometric accuracy of CMA

Where: $\Theta_{m}$-readings from angular measurement systems; $A_{m}, B_{m}, C_{m}-$ unit vectors of direction of the measuring stylus; $\mathrm{X}_{\mathrm{m}}, \mathrm{Y}_{\mathrm{m}}, \mathrm{Z}_{\mathrm{m}}$ - coordinates obtained from the manufacturer's software (GDS or RDS); $\mathrm{X}_{\mathrm{ni}}, \mathrm{Y}_{\mathrm{ni}}, \mathrm{Z}_{\mathrm{ni}}-$ coordinates obtained from the length standard; $1_{\mathrm{m}}$ - distance of axis $\mathrm{z}_{\mathrm{m}-1}$ from axis $\mathrm{z}_{\mathrm{m}}$ measured along axis $\mathrm{x}_{\mathrm{m}} ; \alpha_{\mathrm{m}}$ - the angle between the axes $\mathrm{z}_{\mathrm{m}-1}$ and $\mathrm{z}_{\mathrm{m}}$ measured about an axis $\mathrm{x}_{\mathrm{m}} ; \lambda_{\mathrm{m}}$ - distance of axis $\mathrm{x}_{\mathrm{m}-1}$ from axis $\mathrm{x}_{\mathrm{m}}$ measured along axis $\mathrm{z}_{\mathrm{m}-1} ; \mathrm{D}_{\mathrm{m}}-$ length read from the standard. 


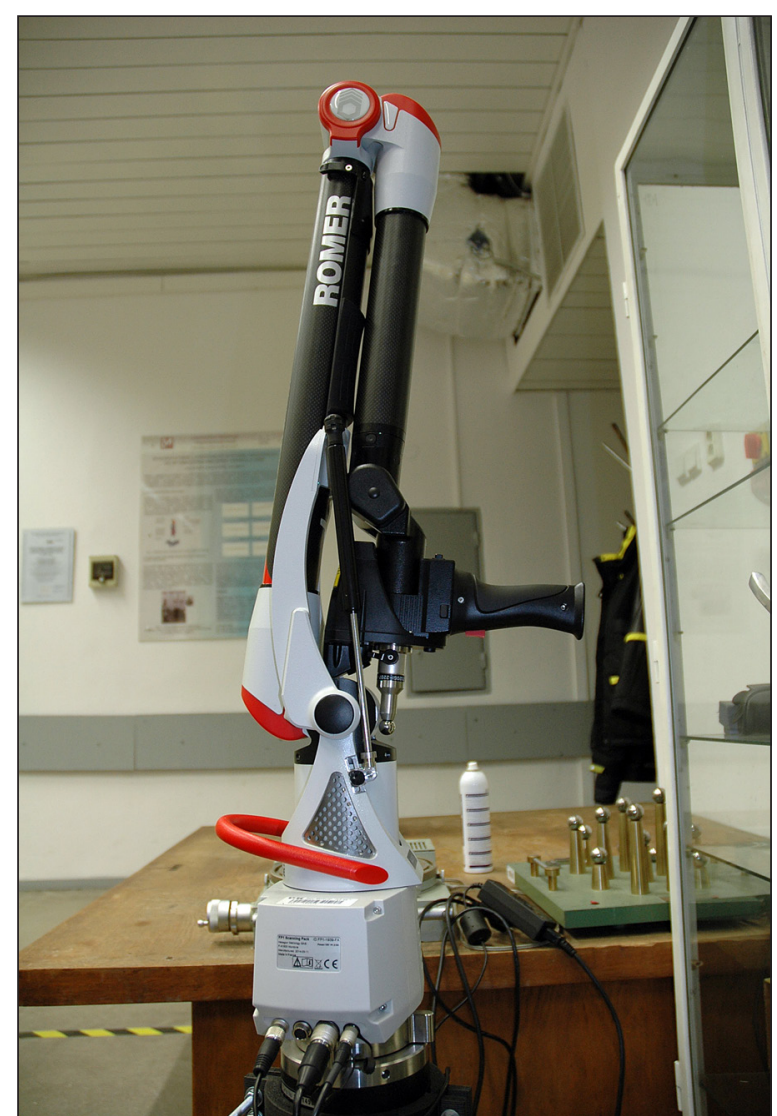

Fig 3a. Coordinate measuring arm RA7320SI

repeatability conditions using the multifeature check (Fig. 3b), developed and manufactured especially in need of validation of coordinate measuring methods.

Validation covered in its scope the results, together with the calculated uncertainties, obtained by measuring three measurands: distance $100 \mathrm{~mm}$, and two diameters $25 \mathrm{~mm}$ and $35 \mathrm{~mm}$ of the multifeature check.

To validate metrological model, including specific results, the reference values should be chosen, called the limit values, that will come together to the established validation model. In this case, the reference values with calculated uncertainties are the values obtained from measurements of the same measurands of multifeature check but using validated multi-position method.

\section{Validation model - the acceptance criterion of metrological model of CMA}

The test of metrological compatibility is used to assess the significance of the difference between two or more results which are traceable to the same reference. According to the [10-12] and definition of metrological compatibility, the set of results $\left[\mathrm{x}_{1}, \mathrm{u}\left(\mathrm{x}_{1}\right)\right],\left[\mathrm{x}_{2}, \mathrm{u}\left(\mathrm{x}_{2}\right)\right], \ldots,\left[\mathrm{x}_{\mathrm{n}}, \mathrm{u}\left(\mathrm{x}_{\mathrm{n}}\right)\right]$ for

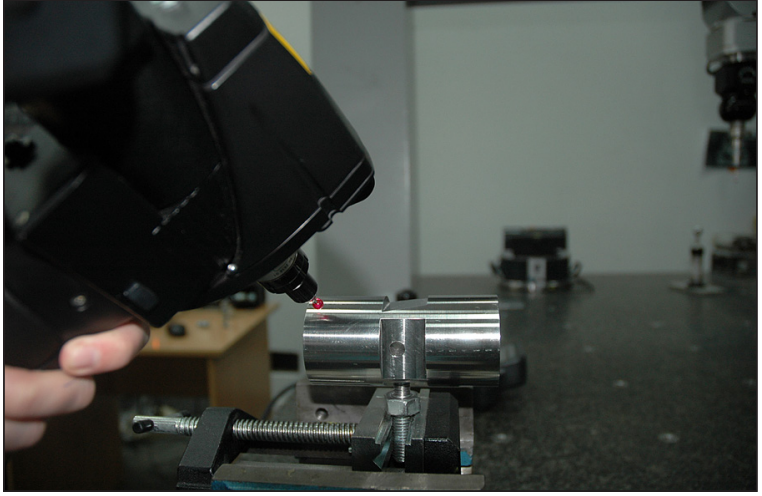

Fig. 3b. Measurements using multifeature check

the same measurand is metrological compatible if they fulfill the condition (7):

$$
\frac{\left|x_{i}-x_{R}\right|}{\sqrt{u^{2}\left(x_{i}\right)+u^{2}\left(x_{R}\right)-2 r\left(x_{i}, x_{R}\right) u\left(x_{i}\right) u\left(x_{R}\right)}} \leq \kappa
$$

where: $x_{R}, u\left(x_{R}\right)$ - the reference values with the standard uncertainties,

$r\left(x_{i}, x_{R}\right)$ - correlation coefficient between the variables $x_{i}, x_{R}$,

$\kappa$ - the threshold which conventional value is 2 .

If the condition is fulfilled, we can confirm the insignificant differences between the measured values $\mathrm{x}_{1}, \ldots, \mathrm{x}_{\mathrm{n}}$ in a view of the uncertainties $\mathrm{u}\left(\mathrm{x}_{1}\right), \ldots, \mathrm{u}\left(\mathrm{x}_{\mathrm{n}}\right)$.

In this process of validation we have the pair $\left(\mathrm{x}_{1}, \mathrm{u}\left(\mathrm{x}_{1}\right)\right),\left(\mathrm{x}_{\mathrm{R}}, \mathrm{u}\left(\mathrm{x}_{\mathrm{R}}\right)\right)$ where $\mathrm{x}_{1}$ is the mean value with its uncertainty $u\left(x_{1}\right)$ for the given measurand using metrological model of CMA and $x_{R}$ is the mean value with its uncertainty $u\left(x_{R}\right)$ for the given measurand using the reference multi-position method (Table 1, Table 2).

\section{CONCLUSIONS}

The developed metrological model of CMA was checked using the most closely appropriate model of validation. The comparison shows the insignificance of differences between the obtained results of both: metrological model of CMA and multi-position method. It evidently proves the correctness of the development of metrological model of CMA. The use of appropriate quality multifeature check also had a significant impact on the results. This check is now the most accurate measurement length check and its use for this validation process was most suitable. 
Table 1. The results for metrological model of CMA and validated multi-position method

\begin{tabular}{|c|c|c|c|c|c|}
\hline Metrological model of CMA & $x_{i}$ & $u\left(x_{i}\right)$ & Multi-position method & $x_{R}$ & $u\left(x_{R}\right)$ \\
\hline $25 \mathrm{~mm}$ & 24.9725 & 0.0124 & $25 \mathrm{~mm}$ & 24.9679 & 0.0127 \\
\hline $35 \mathrm{~mm}$ & 35.0215 & 0.0226 & $35 \mathrm{~mm}$ & 35.0423 & 0.0164 \\
\hline $100 \mathrm{~mm}$ & 99.9707 & 0.0241 & $100 \mathrm{~mm}$ & 99.9367 & 0.0198 \\
\hline
\end{tabular}

Table 2. The results of the metrological compatibility test

\begin{tabular}{|c|c|c|c|}
\hline Metrological model of CMA & $r\left(x_{i}, x_{R}\right)$ & $\frac{\left|x_{i}-x_{R}\right|}{\sqrt{u^{2}\left(x_{i}\right)+u^{2}\left(x_{R}\right)-2 r\left(x_{i}, x_{R}\right) u\left(x_{i}\right) u\left(x_{R}\right)}}$ & $\leq \kappa$ \\
\hline $25 \mathrm{~mm}$ & 0.0167 & 0.2630 & 2 \\
\hline $35 \mathrm{~mm}$ & 0,0351 & 0.7568 & 2 \\
\hline $100 \mathrm{~mm}$ & -0.1199 & 1.0329 & 2 \\
\hline
\end{tabular}

\section{Acknowledgments}

Reported research were realized within confines of project financed by Polish National Centre for Research and Development No: LIDER/024/559/L-4/12/NCBR/2013.

\section{REFERENCES}

1. Gąska A., Krawczyk M., Kupiec R., Ostrowska K., Gąska P., Sładek J.: Modeling of the residual kinematic errors of Coordinate Measuring Machines using Laser Tracer system. International Journal of Advanced Manufacturing Technology, 2014, DOI: 10.1007/s00170-014-5836-1.

2. Ostrowska K., Szewczyk D., Sładek J.: Determination of operator's impact on the measurement done using coordinate technique. Advances in Science and Technology Research Journal, 7(20), 2013, 16-21, DOI: 10.5604/20804075.1073045.

3. Ostrowska K., Gąska A., Sładek J.: Determining the uncertainty of measurement with the use of a Virtual Coordinate Measuring Arm. International Journal of Advanced Manufacturing Technology, 2013, DOI: 10.1007/s00170-013-5486.

4. Sładek J., Ostrowska K., Gąska A.: Modeling and identification of errors of coordinate measuring arms with the use of a metrological model. Measurement, 46, 2013, 667-679, DOI: 10.1016/j. measurement.2012.08.026.

5. Sładek J., Ostrowska K., Gacek K., Bryndza M.: Designation of operator impast on errors of measu- rements realized by coordinate measuring arm. In: J. Sładek, W. Jakubiec (Eds.) Advances in Coordinate Metrology, Bielsko-Biała 2010, 130-137.

6. Sładek J., Ostrowska K., Gąska A.: Wirtualne współrzędnościowe ramie pomiarowe. Pomiary Automatyka - Kontrola, 54(01), 2010.

7. Sładek J., Ostrowska K., Gąska A., Gacek K., Kmita A.: Model matematyczny opisu dokładności współrzędnościowych ramion pomiarowych. W: J. Gawlik (red.) Innowacyjne systemy produkcyjne. Monografia, 2009.

8. Sładek J., Ostrowska K., Gacek K.: Kinematic metrological model of the coordinate measuring arm (MCMA). In: XIX World Congress Fundamental and Applied Metrology IMEKO, Lisbon, Portugal 2009.

9. Sładek J.: Dokładność pomiarów współrzędnościowych. Wydawnictwo Politechniki Krakowskiej, Kraków 2011.

10. Kacker R.N., Kessel R., Sommer K.D., Bian X.: Comparison of statistical consistency and metrological compatibility. In: XIX World Congress Fundamental and Applied Metrology IMEKO, Lisbon, Portugal, 2009, 6-11.

11. Kacker R.N., Kessel R., Sommer K.D.: Assesing differences between results determined according to the Guide of Expression of Uncertainty in Measurement. Journal of Research of the National Institute of Standards and Technology, 115, 2010, 453-459.

12. Kacker R.N., Kessel R., Sommer K.D.: Metrological compatibility and statistical consistency. In: $10^{\text {th }}$ International Symposium on Measurement and Quality Control, September 5-9, 2010. 